\title{
A INTERNET E A EDUCAÇÃO A DISTÂNCIA
}

\author{
Eliane Regina Costa Oliveira
}

\begin{abstract}
Mestre em Engenharia da Produção pela Universidade Federal de Santa Catarina. Professora de Inglês no Centro Acadêmico de Línguas Estrangeiras Modernas do CEFET-PR
\end{abstract}

\begin{abstract}
This paper aims at showing the importance of Web-based education and its characteristics. As a number of distance courses are offered nowadays using several means of communication/information, delivering courses via the Internet offers a wide variety of advantages, offering students new flexible means of interacting with teachers and other students. This paper also shows some problems in the distancelearning environment.
\end{abstract}

Key words: distance education, Internet, interaction, means of communication/information.

\section{RESUMO}

O objetivo deste artigo é mostrar a importância da educação a distância via Internet e suas características. Atualmente, um grande número de cursos a distância está sendo oferecido, utilizando diversos meios de comunicação e informação. Os cursos via Internet trazem uma variedade de vantagens, oferecendo aos alunos meios novos e mais flexíveis de interação com professores e os outros alunos. Este trabalho também aponta alguns problemas no campo do ensino a distância.

Palavras chaves: educação a distância, Internet, meios de comunicação e informação.

\section{A INTERNET E A EDUCAÇÃO A DISTÂNCIA}

As metáforas centrais da relação com o saber são hoje a navegação e o

surf, que implicam uma capacidade de afrontar as ondas,os redemoinhos

as correntes e os ventos contrários sobre uma extensão plana, sem

fronteiras e sempre mutante.

Pierre Lévy

\section{INTRODUÇÃO}

O homem tem vivenciado uma sucessão de eras e cada uma delas tem características que determinam o seu futuro. (Toffler, 1990). Estas são a era da agricultura, a era industrial e a era da informação ou da tecnologia; esta última forma, segundo Grant (1994), uma cultura onde a pessoa não precisa estar presente para se envolver. Esta é uma mudança diferente porque seu principal agente não é a violência, como em outras revoluções, mas a comunicação. 
Pela primeira vez na humanidade, a maior parte das competências adquiridas por uma pessoa no início de seu percurso profissional estarão obsoletas ao fim de sua carreira. (Lévy, 1993). Portanto essa pessoa precisa se atualizar sempre e para isso é necessário o seu acesso a meios de comunicação ricos e interativos, que lhe proporcionem oportunidades para o crescimento intelectual e profissional.

As tecnologias trazem informações novas, nos ligam com o mundo e nos atingem totalmente, por estarem em contínuo aprimoramento na arte da comunicação com os mais diversos tipos de pessoas, procurando ser sempre os campeões nas pesquisas de preferência, destacando-se entre outros, a televisão.

Vygotsky (1978) diz que o desenvolvimento escolar de uma criança depende do acompanhamento de um adulto ou de colegas mais capacitados. $\mathrm{O}$ autor estava teorizando sobre educação como atividade fundamentalmente humana, como explica Moll (1990). O que ele não imaginava, na era pré computador em que viveu, era que o instrutor para o aluno não precisava necessariamente ser humano e que poderia estar com o aluno a qualquer tempo e lugar, no sentido virtual.

\section{INTERNET}

Steven Jones (1997) afirma que uma vez que estamos todos ligados no ciberespaço estamos então infinitamente distantes uns dos outros quando não estamos nos comunicando.

Hoje, é na Internet, que se cria um meio mundial de comunicação, onde se pode encontrar quase todo o tipo de informação num piscar de olhos, há trocas de informações e tudo nela está em constante construção e modificação. Ela se desenvolveu sem a presença de um projetista de plantão, não há um comando e todas as suas peças se ajustam de modo admirável. (Negroponte, 1995)

Há grupos que introduzem novas informações e pesquisam as necessidades da rede, como a Internet Society e InterNIC, segundo Jones (1995).

Em resposta a um questionário sobre Internet ( anexo 1) um grupo de adolescentes com idades variando entre 15 e 17 anos, definiu a Internet de várias maneiras, desde a tradicional rede mundial de computadores até simples expressões como: "Legal!". Outras definições:

"É uma coisa legal, que une pessoas de diferentes culturas". "É um passatempo." "Bom artifício para as empresas fazerem propaganda ." "Só dá telefone ocupado ou provedor muito lento." "Um mundo em minha casa." "Um oceano de informações onde você pode se integrar com todo o mundo". "Facilidade ... demora." "Um lugar onde se encontra de tudo. " "Um acesso facilitado a tudo que se quer, que está dentro de um universo ilimitado." "Algo muito grande em outro relativamente pequeno." "Uma ligação entre o mundo, onde não há fronteiras." "Um meio para "estar" em vários lugares rapidamente." "Uma ligação entre o eu e o mundo virtualizado (sic) diante de uma tela" . "Um refúgio para pessoas que não conseguem se relacionar."

Estas são em sua maioria , definições indicando uma idéia positiva sobre a Internet. Os adolescentes falam sobre tempo e espaço virtuais sem se darem conta disso. Dentro 
desse grupo muitos declararam gostar de "navegar sem rumo" na Internet, especialmente para descobrirem lugares novos.

Negroponte (1995) escreve que, no mundo digital , as distâncias significam cada vez menos e um usuário da Internet nem se lembra que elas existem . Em suas definições, os adolescentes colocaram expressões indicando isso: oceano ilimitado, diferentes culturas, lugar, mundo sem fronteiras, etc.

Continuando com Negroponte, "Os bits de controle desse futuro digital estão mais do que nunca nas mãos dos jovens. Nada seria capaz de me deixar mais feliz do que isso." Como a história da Internet ainda está sendo escrita, são esses adolescentes que têm nas mãos uma ferramenta em rápido desenvolvimento e cabe a eles a responsabilidade de melhorá-la, mas prestando atenção às perguntas de Steven Jones (1997) "O que escolhemos deixar para trás quando adotamos e adaptamos a nova tecnologia de mídia? O que podemos ganhar com nosso novo investimento?"

São perguntas que dizem respeito à sociologia, ciências políticas, economia, comunicação e história - todas estas ciências afetam diretamente o homem como ator na sociedade, no mundo em que atua.

Estes jovens entrevistados, declaram também usar na Internet o correio eletrônico, mandando e recebendo mensagens; o chat, para conversarem com pessoas que eles não conhecem; e ainda para pesquisar trabalhos escolares. Estas respostas demonstram que os jovens gostam muito de se comunicar pela Internet, passando seus pensamentos, emoções e informações instantaneamente através de distâncias muito grandes.

Aqui surge a pergunta que preocupa tanto os estudiosos, se esse modelo de comunicação pode levar as pessoas à solidão, a querer deixar relacionamentos pessoais de lado para ficarem conectadas à rede, se esquecendo delas próprias?

Parece que os jovens entrevistados não estão agindo assim, porque em primeiro lugar vem a comunicação com outros, via chat (em tempo real), e-mail (assíncrono ) e, em entrevista informal, contam que tudo começa com o e-mail, depois o chat, o telefone e mais tarde o encontro pessoal (quando possível, se não estiverem geograficamente muito distantes). Portanto, eles dão bastante atenção ao encontro pessoal, mas quando as barreiras geográficas são grandes, continuam juntos no tempo e espaço infinitos que a Internet oferece.

Estes adolescentes se encaixam nos dois momentos do computador que Sherry Turkle (1995) mostra. Ele se destaca como uma ferramenta, ajudando-nos a escrever, gerir contas bancárias e a nos comunicar com outras pessoas; e, ainda, o computador é um novo meio no qual podemos projetar nossas idéias e fantasias, nos conduz ao mundo virtual. É aqui, onde se encontra a Internet, que acontece a comunicação democrática, sem fronteiras, assíncrona, isto é, onde tempo e espaço não são fatores importantes para que a comunicação se realize.

Ë esse lugar, o ciberespaço, que aos poucos está sendo descoberto para a expansão da escola. Murray (1997) coloca que "o computador é o filho da impressão, o resultado de vinte séculos de organização, investigação coletiva e da invenção do processo de impressão." 


\section{EDUCAÇÃO A DISTÂNCIA}

A utilização desses novos recursos de informação por educadores nas diversas áreas do conhecimento está se tornando uma realidade e os alunos, por sua vez, são preparados para viverem numa sociedade em constantes mudanças. A aquisição do conhecimento é privilegiada pela facilidade e rapidez com que este é difundido pelos meios de comunicação. E o professor, através da reelaboração crítica de seu papel, torna-se um pesquisador/facilitador do processo ensino-aprendizagem, motivando seus alunos a alçarem vôos mais altos através da pesquisa facilitada pela Internet. (Demo,1993 )

Na mais recente revolução, a da tecnologia, o crescimento de cursos de educação a distância que utilizam os diversos meios tecnológicos, como a televisão, vídeo, computador, Internet, vídeoconferência vêm ocorrendo de forma muito rápida e a educação a distância está se tornando também uma ferramenta poderosa no processo da construção da aprendizagem. Com o potencial dessas modernas tecnologias sendo direcionado para o ensino já se pode notar resultados positivos, porque elas misturam sons e visualização de informações complexas além da contextualização dos diferentes conteúdos explorados com características individuais ou coletivas.

Willis (1993) afirma que o que nós não sabemos sobre aprendizagem a distância, excede o que sabemos sobre ela. Para ter sucesso, educação a distância requer esforços integrados de diversos participantes, principalmente dos alunos. Satisfazer as suas necessidades é a pedra angular da educação a distância e o teste pelo qual todos os esforços neste campo deveriam ser julgados.

Moran (1994) escreve que muitos educadores e intelectuais sentem horror e criticam de forma radical os meios de comunicação, enquanto que, para outros, esses mesmos meios significam modernidade, lazer, deslumbramento, relação dinâmica com o mundo. Como são posições contrárias, para tomar uma posição, um dos caminhos é o de se fazer uma leitura crítica dos meios de comunicação nas diversas áreas do conhecimento, analisando-os tanto do ponto de vista estético como de conteúdo.

O que é educação a distância?

Destacam-se alguns pontos importantes da conceituação de educação a distância no Decreto n. ${ }^{\circ} 2494$ de 10/02/98, artigo $1^{\circ}$, que são: "a educação a distância é uma forma de ensino que facilita a aprendizagem, com mediação de recursos didáticos sistematicamente organizados, apresentados em diferentes suportes de informação utilizados isoladamente ou combinados e veiculados pelos diversos meios de comunicação. "

Alguns autores definem educação a distância como o uso de meios de comunicação impresso ou eletrônico para o ensino, quando professores e alunos estão separados pelo tempo e/ou lugar. (Eastmond,1995). Outros autores definem educação a distância como "trazer pessoas - e vídeo imagens de pessoas - para o mesmo espaço eletrônico e assim elas podem se auxiliar mutuamente na aquisição do conhecimento"; e ainda, "um sistema e processo que conecta estudantes com pesquisas prescritas."(Filipczak, 1995). Estas definições implicam na colocação do aluno no centro do processo ensino/aprendizagem. 
No início, os principais interessados em cursos de educação a distância eram adultos, que pelos mais diferentes motivos não puderam frequientar as tradicionais instituições de ensino, mas agora qualquer pessoa é um aluno em potencial. Em pesquisas realizadas sobre as qualidades positivas do curso, há os mais variados motivos pelos quais o aluno entra em um curso a distância: facilidade de acesso, isto é, ele não precisa se deslocar para assistir as aulas, facilidade de horário, situação motivacional, interesses e outros aspectos referentes a tempo e espaço, que com o advento da educação a distância, tornam o acesso ao ensino possível.

Este tipo de ensino pode ser tão eficiente quanto o tradicional quando o método e as tecnologias usadas são apropriadas, havendo interação entre os estudantes, destes com o professor e o professor lhes dá um feedback de tudo o que for realizado durante o curso.

Quanto à tecnologia, deve-se utilizar aquela ou aquelas que estão disponíveis, sempre com um planejamento detalhado sobre as necessidades do aluno, as dificuldades ou facilidades do professor e as exigências do conteúdo, antes da escolha definitiva do meio. Há muitas pesquisas e projetos visando à melhor utilização dos meios de mídia a serem utilizados em cursos a distância, mas se limitam, em sua maioria, a considerar as técnicas, privilegiando o estudo das mídias e forma de torná-las mais eficientes. Já a nível de aluno, há uma deficiência de pesquisas. O estudo do aluno e suas motivações, necessidades e expectativas com relação ao curso é um ponto muito importante, assim como a pertinência do conteúdo a ser ministrado e a habilidade do professor na transmissão das informações.

A escolha da mídia é sempre de relevante importância para o sucesso do curso. O programa deve começar com um planejamento cuidadoso com a compreensão dos objetivos do curso e as necessidades dos estudantes. Para que os objetivos sejam atingidos, deve haver a união de esforços de alunos, professores, administradores e de todo o pessoal de apoio. Um curso a distância não surge espontaneamente, mas ele vai se desenvolvendo por meio de esforços conjuntos desses indivíduos e da instituição. $\mathrm{O}$ tipo de mídia a ser utilizada normalmente não é somente uma, mas uma mistura de várias, cada uma servindo a um propósito.

Material impresso é o componente básico, fornecendo material de apoio: leituras, programa, textos do curso, horários, etc.

Áudio ou vídeoconferência favorece os encontros em tempo real entre professor e alunos, facilitando o encontro com palestrantes convidados.

Conferência pelo computador ou correio eletrônico pode ser usado para o envio de mensagens, trabalhos acadêmicos e comunicação particular, podendo ser usado para melhorar a interação entre estudantes.

Fitas de vídeo gravadas podem ser usadas para apresentação de palestras e conteúdos que necessitam de visualização. para a avaliação individual do aluno. (Willis, 1995)

\section{A INTERNET COMO MEIO PARA A EDUCAÇÃO A DISTÂNCIA}


Talvez a Internet e a Web, mais do que qualquer outro meio de informação, ajudem a derrubar barreiras de tempo e espaço no processo ensino-aprendizagem. Os usos educacionais para a Internet estão crescendo, pela facilidade de acesso e pela sua habilidade de mostrar gráficos, texto e som em um só aparelho - o computador.

Há inúmeras instituições tradicionais e não tradicionais (como, nos EUA, a University On Line e a Global Network Academy ou a Open University, na Inglaterra e muitas outras) oferecendo programas de graduação e pós-graduação on line. Esses cursos utilizam a Internet pela facilidade de acesso mundial e usam as ferramentas da Web ( como o correio eletrônico; newsgroups) para discussão de tópicos especiais; download, para cópia de arquivos; monitoria interativa; conferência interativa em tempo real através de sistemas MOO ou Internet Relay Chat; intranet, que são sites protegidos para treinamento de funcionários de empresas; informática para uso de dados, catálogos, websites, material com informações disponíveis on line.( Eric Digest 395214 96).Quando o curso a distância não é via Internet, ele a utiliza como meio de apoio por dispor dessas ferramentas de rápido e fácil acesso para todos os alunos.

Por outro lado, os alunos precisam saber usar o computador com seus programas e a acessar a Internet e suas facilidades.

Alguns elementos que os alunos geralmente destacam em cursos a distância, conforme pesquisas já realizadas, são a assincronicidade ( acessar o curso a hora que quiser), apoio do grupo (camaradagem na experiência do novo aprendizado), reflexão ( ter tempo para pensar bastante antes de responder, usando a linguagem digital), controle (sentir-se independente nos estudos), interatividade (dar e receber feedback das mensagens on line), texto (envolver-se em atividades de leitura e escrita intensivas) e democracia (sentimento de que cada participante teve tempo equivalente on line). (Eastmond, 1998).

Por outro lado, também há obstáculos nos cursos via Internet. Muitas vezes os alunos se sentem frustrados por dificuldades como problemas técnicos, instruções ambíguas no site ou e-mail, pouco ou nenhum feedback do instrutor; as discussões, às vezes, se tornam mais competitivas do que colaborativas. Todos esses pontos, positivos e negativos deverão ser avaliados ao final de cada etapa do curso, visando ao melhoramento do programa.

\section{CONCLUSÃO}

A educação a distância mediada por computador ainda é um meio em desenvolvimento, em estudo. Não se pode dizer que seja melhor ou pior que os métodos tradicionais de ensino. Bates (1994) escreve que ainda não foi provado que as tecnologias avançadas sejam pedagogicamente mais eficientes que as antigas e fica também a questão se as tecnologias modernas podem melhorar a pedagogia sem muito esforço.

Como já foi dito anteriormente, precisamos de mais pesquisas sobre educação a distância como prática social significativa, e também sobre o comportamento dos estudantes face à tecnologia nos cursos onde o contato com professores e colegas não é face-a-face como os tradicionais. 
O computador (Internet) funciona aqui como o mediador entre o aluno, o professor e os conteúdos colaborando com o sucesso do processo ensino-aprendizagem. É através da super autoestrada da Internet ( navegando ou surfando) que o aluno pode construir ou descobrir novos caminhos no ciberespaço, adquirindo diferentes competências acessíveis on line.

"À medida que os seres humanos se confundem cada vez mais com a tecnologia e uns com os outros através da tecnologia, as velhas distinções entre o que é especificamente humano e o que é especificamente tecnológico tornam-se mais complexas." (Sherry Turkle). 


\section{REFERÊNCIAS BIBLIOGRÁFICAS}

BRASIL. Educação a Distância. Decreto n. ${ }^{\circ}$ 2.494, de 10 de fevereiro de 1998.

DEMO, Pedro. Desafios Modernos da Educação. Petrópolis: Vozes,1993.

Questões para a Teleducação. Petrópolis: Vozes, 1998.

EASTMOND, Daniel. Adult Learners and Internet-based Distance Education. In:

Adult Learning and the Internet. New Directions for adult and continuing education, number 78, summer 1998, Jossey-Bass Publishers.

JONES, Steven G. The Internet and its Social Landscape. In: Jones, S. G. Virtual Culture. Identity and Communication in Cybersociety London: Sage, 1997.

LÉVY, Pierre. A cultura da Informática e a Educação. Tradução do Núcleo de Educação Aberta e a Distância, UFMT, 1997, (mimeo).

As Tecnologias da Inteligência. O Futuro do Pensamento na era da Informática. Rio de Janeiro: Editora 34 1993, caps. 7 a 10.

O que é o Virtual? Tradução Paulo Neves, São Paulo:Editora 34, 1996.

NEGROPONTE, Nicholas. A Vida Digital. Tradução Sérgio Tellardi São Paulo:

Companhia das Letras, 1995.

RODRIGUES, Rosângela S. Modelo de Avaliação para Cursos no Ensino a

Distância: estrutura, aplicação e avaliação. Dissertação de Mestrado,

Florianópolis, PPGEP,1998, URL:

http://www.eps.ufsc.br/disserta98/roser/index.htm

TIFFIN, John. RAJASINGHAM,Lalita. Search of the Virtual Class. London:

Routledge, 1995.

TURKLE, Sherry. A Vida no Ecrã - A Identidade na Era da Internet. Tradução de Paulo Faria. Lisboa: Relógio D'Água Editores, 1997. Introdução e Cap. 1. 
WILLIS, Barry. Distance Education at a Glance. Series of Guides prepared by Engineering of Outreach at the Universityof Idaho, 1995. URL:

www.uidaho.edu/evo/distglan.html (Acessado em21/04/00)

Instructional Development for Distance Education. Syracuse, New

York: ERIC (ED 351007), 1992. 